\title{
Sucesión microbiana durante la fermentación espontánea de cacao en unidades productivas
}

\section{Microbial Succession During the Spontaneous Fermentation of Cocoa in Productive Units}

\author{
Estefanía García-González ${ }^{1}$, Andrés Felipe Ochoa-Muñoz ${ }^{2}$, Constanza Montalvo-Rodríguez ${ }^{3}$, Ginna \\ Alejandra Ordoñez-Narváez ${ }^{4}$ y Liliana Londoño-Hernández ${ }^{5}$
}

\begin{abstract}
Resumen
La fermentación del cacao es determinada por el crecimiento de sucesiones de diversos grupos microbianos que varían de una región a otra. En el presente estudio se realizó una caracterización de las muestras tomadas de fermentaciones de unidades productivas del Valle del Cauca a las cuales se les midió la concentración de levaduras, bacterias lácticas, bacterias acéticas y aerobios mesófilos durante 5 días. Adicionalmente se determinó la concentración de azúcares reductores y pH tanto del cotiledón como de la testa mucilaginosa. Finalizada la fermentación se determinó el grado de fermentación (prueba de corte e índice de fermentación). Se presentó un crecimiento de levaduras, bacterias acéticas y bacterias lácticas constante durante los 5 días de fermentación evaluados, a excepción del muestreo 1 que presentó un descenso en la concentración de BAA. Se presentaron temperaturas promedio de fermentación de 26,27 y $25{ }^{\circ} \mathrm{C}$, consumo de azúcares fue de $64.40,88.78$ y $98.27 \%$ para los puntos de muestreo 1,2 y 3 , respectivamente. Conocer el comportamiento de los grupos microbianos y sus respuestas bioquímicas, permiten entender las relaciones entre el crecimiento de la microbiota del cacao y su calidad final, que a futuro permitan mejorar la calidad de los productos derivados.
\end{abstract}

Palabras clave: levaduras, bacterias lácticas, bacterias acéticas

\begin{abstract}
Cocoa fermentation is determined by the growth of successions of diverse microbial groups that vary from one region to another. In the present study, a characterization of the samples taken from fermentations of productive units of Valle del Cauca was carried out, to which the concentration of yeasts, lactic acid bacteria, acetic acid bacteria and mesophilic aerobes was measured during 5 days. Additionally, the concentration of reducing sugars and $\mathrm{pH}$ of both the cotyledon and the mucilaginous testa were determined. At the end of fermentation, the degree of fermentation was determined (cut-off test and fermentation index). Yeast, acetic acid bacteria and lactic acid bacteria growth was constant during the 5 days of fermentation evaluated, with the exception of M1, which showed a decline in BAA concentration. Average fermentation temperatures of 26,27 and $25^{\circ} \mathrm{C}$, sugar consumption of 64.40 , 88.78 and $98.27 \%$ were presented for sampling points 1, 2 and 3, respectively. Knowing the behavior of the microbial groups and their biochemical responses allows understanding the relationships between the growth of the cocoa microbiota and its final quality, which in the future will allow improving the quality of the derived products.
\end{abstract}

Keywords: yeast, lactic bacteria, acetic bacteria

Recepción: 15-dic-2020

Aceptación: 27-jun-2021

\footnotetext{
${ }^{1}$ Servicio Nacional de Aprendizaje (SENA), Centro de Biotecnología Industrial, Palmira, Colombia. Grupo de investigación BITI. M.Sc. Ingeniería de Bioprocesos y Biotecnología, Palmira, Colombia.

${ }^{2}$ Universidad de Valparaíso, Instituto de Estadística, Valparaiso, Chile. Grupo de investigación BITI. M.Sc. Estadística, Santiago de Cali, Colombia.

${ }^{3}$ Servicio Nacional de Aprendizaje (SENA), Centro de Biotecnología Industrial, Palmira, Colombia. Grupo de investigación BITI, Ph.D. ingeniería de alimentos, Palmira (Colombia). Correspondencia: cmontalvor@ sena.edu.co

${ }^{4}$ Universidad Nacional Abierta y a Distancia (UNAD), Palmira, Colombia. Grupo de investigación BITI. Ph.D. Ciencias agrarias, Palmira, Colombia.

${ }^{5}$ Universidad Nacional Abierta y a Distancia (UNAD), Palmira, Colombia. Grupo de investigación BITI. Ph.D. Ciencia y tecnología de alimentos, Palmira, Colombia.
} 


\section{Introducción}

El mercado del cacao fino y de aroma representa el 5\% de la producción mundial de cacao, aunque pequeño, es un mercado interesante que demanda más calidad. Los principales productores de cacao fino y de aroma son América Latina y el Caribe, entre los cuales se encuentra Colombia [1]. Para asegurar la calidad de cacao se deben tener en cuenta aspectos genéticos, agronómicos (variedad de cacao, clima, suelo, etc) y de poscosecha (cosecha, fermentación y secado). En la poscosecha una de las etapas fundamentales es la fermentación, cuyo paso es decisivo en la producción de un chocolate de calidad [2], sin embargo, la fermentación de cacao, sigue siendo un procedimiento empírico, para muchos productores que poseen deficiencias tecnológicas, y como consecuencia se generan pocas ganancias para los productores de cacao, ya que se presenta una calidad variable [3] y los procesadores deben variar las formulaciones de los productos derivados [4].

Las semillas de cacao se componen de un embrión con dos cotiledones de almacenamiento grandes (cotiledón) protegidos por una cáscara de semilla flexible (testa mucilaginosa) [5]. Con la fermentación, se inicia un proceso de conversión de azúcares y ácido cítrico presentes en la pulpa de los granos en ácidos orgánicos por la acción de microorganismos [6]. Además, la fermentación cumple diversas funciones en el grano de cacao: despectinización de la pulpa, disminución de la humedad, muerte del embrión, desarrollo de precursores de sabor y aroma, y disminución de astringencia y amargor [7]. En este proceso, la ecología microbiana en la fermentación, está determinada por el crecimiento sucesional de diversos grupos microbianos como levaduras, bacterias ácido acéticas (BAA), bacterias ácido lácticas (BAL) y otros grupos microbianos como hongos filamentosos y bacterias del género Bacillus [5, 7].

En una primera fase de la fermentación las levaduras y BAL predominan por las condiciones iniciales del medio (alta concentración de azúcares, medio ácido y anaerobiosis), lo que ocasiona la despectinización de la pulpa, y esto permite la entrada de oxígeno a la masa de fermentación [8]. Los productos de la fermentación heterofermentativa del ácido cítrico por parte de las BAL, genera un ligero incremento en el $\mathrm{pH}$, lo que promueve el crecimiento de las BAA [9]. Estos procesos bioquímicos que se generan en la fermentación generan cambios que se ven reflejados en parámetros fisicoquímicos que influencian en la calidad del grano $(\mathrm{pH}$, acidez, grado de fermentación, índice de grano, índice de mazorca, entre otros) [10]. Para el diseño de un proceso de fermentación estandarizado, se requiere evaluar la dinámica microbiana [11]. Por lo anterior, el objetivo de este trabajo fue estudiar la dinámica microbiana de fermentaciones espontáneas de cacao de unidades productivas en el municipio de Florida (Valle del Cauca) y aislar microorganismos de interés para futuras aplicaciones como cultivos iniciadores.

\section{Metodología}

\subsection{Muestreo}

Las fermentaciones se realizaron en unidades productivas de la zona rural de Florida, departamento del Valle del Cauca. Se identificaron tres puntos de muestreo diferentes de granos de cacao fermentado y seco (M1, M2 y M3). Los muestreos de fermentación se realizaron bajo las características mencionadas en el Tabla 1.

\subsection{Material vegetal}

Se emplearon mazorcas de Cacao (Theobroma cacao) tipo clones de trinitario, colectadas en estado de maduración fisiológico y se rompieron con herramientas de corte artesanal. Las mazorcas de cacao fueron cosechadas con una tijera de poda. Los granos de cacao fueron desgranados manualmente y transportados en recipientes plásticos hacia el lugar de fermentación.

\subsection{Fermentación}

El seguimiento a la fermentación se realizó durante 5 días. Diariamente se tomaron muestras de cacao en fermentación en las zonas de producción, se empacaron en bolsas plásticas y se llevaron a los laboratorios del Centro de Biotecnología Industrial para análisis fisicoquímicos. Los análisis microbiológicos y químicos fueron realizados por triplicado. 
Tabla 1. Características de muestreos de granos de cacao

\begin{tabular}{|c|c|c|c|}
\hline Parámetro & M 1 & M 2 & M 3 \\
\hline Latitud & $3.2707163^{\circ} 16^{\prime} 14.58^{\prime \prime} \mathrm{N}$ & $3.2640803^{\circ} 15^{\prime} 50.69^{\prime \prime} \mathrm{N}$ & $3.2623113^{\circ} 15^{\prime} 44.32^{\prime \prime} \mathrm{N}$ \\
\hline \multirow[t]{2}{*}{ Longitud } & -76.216476 & -76.211040 & -76.213648 \\
\hline & $12{ }^{\prime} 59.31 ’ \mathrm{~W}$ & $12 ’ 39.74 ” \mathrm{~W}$ & $12 ’ 49.13 ” \mathrm{~W}$ \\
\hline Fecha & Abril 25 al 29 de 2018 & Mayo 16 al 20 de 2018 & Junio 11 al 15 de 2018 \\
\hline Cantidad (kg) & 12 & 10 & 20 \\
\hline Fermentación & $\begin{array}{l}\text { Recipiente cilíndrico de } \\
\text { Polietileno de Alta Den- } \\
\text { sidad de } 20 \text { L. }\end{array}$ & Cajón de madera de $1 \mathrm{~m}^{3}$ & $\begin{array}{l}\text { Recipiente cilíndrico de } \\
\text { Polietileno de Alta Densi- } \\
\text { dad de } 200 \text { L. }\end{array}$ \\
\hline Volteo & $\begin{array}{l}\text { Diario después de las } \\
\text { primeras } 24 \text { horas }\end{array}$ & $\begin{array}{l}\text { Diario después de las } \\
\text { primeras } 24 \text { horas }\end{array}$ & Sin volteo \\
\hline Secado & Sobre lonas en asfalto. & $\begin{array}{l}\text { Marquesina con base de } \\
\text { asfalto. }\end{array}$ & Sobre lonas en asfalto. \\
\hline Observación & $\begin{array}{l}\text { El recipiente plástico fue } \\
\text { tapado con una tabla de } \\
\text { madera. Con orificios } \\
\text { en la parte inferior para } \\
\text { dejar pasar el exudado } \\
\text { del mucilago. }\end{array}$ & $\begin{array}{l}\text { El volumen de } \\
\text { fermentación fue } \\
\text { muy bajo comparado con } \\
\text { la capacidad de la caja de } \\
\text { madera }\end{array}$ & $\begin{array}{l}\text { El recipiente no presenta } \\
\text { orificios para dejar pasar el } \\
\text { exudado del mucilago de } \\
\text { los granos de cacao. }\end{array}$ \\
\hline
\end{tabular}

\subsection{Secado}

Los granos fermentados fueron secados al sol durante 4 días por los productores. Posteriormente, una muestra de $50 \mathrm{~g}$ de granos secos fue llevada a laboratorio de Biotecnología del Sena CBI Palmira para determinación de los siguientes parámetros fisicoquímicos, después del secado: Índice de grano, grado de fermentación visual (El parámetro que permite determinar la adecuada fermentación de los granos)[12] e índice de fermentación [13].

\subsection{Análisis químicos}

A los granos de cacao fresco se les determinó el pH [14], se tomaron 5 granos de cacao y se separó la testa mucilaginosa del cotiledón, se maceró cada uno de los materiales separadamente y se realizó una dilución en $50 \mathrm{ml}$ de agua. Posteriormente se midió el pH con un potenciómetro marca BANTE 210 (China).

Los azúcares reductores se determinaron por el método de DNS [15]. A $90 \mathrm{ml}$ de agua destilada, fueron agregados $10 \mathrm{~g}$ de cacao previamente macerados, la solución se llevó a agitación durante 30 min. A partir de la muestra diluida, se realizaron diluciones sucesivas hasta $10^{-3}$ y se determinó la concentración de azúcares reductores contrastándola con la curva estándar a una absorbancia de $540 \mathrm{~nm}$. La ecuación de la curva fue: $y=0.0014 x+0.025$ con un $\mathrm{R}^{2}=0,997$.

El índice de fermentación se determinó siguiendo la metodología de Gourieva y Tserrevitinov, [13]. Aproximadamente $0.1 \mathrm{~g}$ de la almendra de cacao seca y molida, se extrajo con $50 \mathrm{ml}$ de una solución de metanol: $\mathrm{HCl}$ (97: 3, v/v). El homogeneizado se refrigeró a $8{ }^{\circ} \mathrm{C}$ durante 20 horas en un recipiente protegido de la luz con tapa. Luego se filtró al vacío y el filtrado se leyó en un espectrofotómetro (MAPADA UV-1200, China) a 460 y $525 \mathrm{~nm}$ de absorbancia. El índice de fermentación (IF) se estimó a través de la relación entre las lecturas de absorbancia en los rangos de 460 y $525 \mathrm{~nm}$ (Ecuación 1)

$$
\mathrm{IF}=\frac{\mathrm{Abs}_{460}}{\mathrm{Abs}_{525}}
$$

donde $\mathrm{Abs}_{460}=$ Medida de absorbancia a $460 \mathrm{~nm}$ y $\mathrm{Abs}_{525}=$ Medida de absorbancia a $525 \mathrm{~nm}$.

\subsection{Análisis microbiológico de granos de cacao en fermentación}

Para el recuento de microorganismos, se utilizaron $10 \mathrm{~g}$ de gramos de cacao. Los microorganismos, presentes en el mucilago del grano, fueron separados, extrayendo el mucilago del cotiledón, el cual fue 
macerado y homogeneizado en $90 \mathrm{ml}$ (dilución $10^{-1}$ ) de agua peptona al $0.1 \%$ en un agitador a $140 \mathrm{rpm}$ durante 30 minutos (Merck, EEUU), posteriormente se realizaron diluciones seriadas (v/v) desde $10^{-1}$ hasta $10^{-6}$, según el caso. Se determinó la concentración de levaduras (agar Saboraud cloranfenicol, Sharlau, España), bacterias acido lácticas (agar MRS, Merk, EEUU) + azul de anilina (0,3\%), bacterias acéticas (Agar CARR modificado, expresado en g/L): glucosa, $3 ; \mathrm{CaCO}_{3}$, 10; azul de bromotimol, 0,04; extracto de levadura 10; agar, 20 y etanol 17,5 ml/L [16], [17] y aerobios mesófilos (agar triptona-extracto de levadura). En los medios utilizados para el recuento de bacterias se emplearon $10 \mu \mathrm{g} / \mathrm{mL}$ de cicloheximida (Merk, EEUU) como concentración final en el medio de cultivo. Después de la difusión, las placas se incubaron a $37{ }^{\circ} \mathrm{C}$ durante 48 horas para bacteria láctica y acética. Los cultivos de levaduras y aerobios mesófilos se incubaron a $30{ }^{\circ} \mathrm{C}$ durante 48 horas. Después de la incubación, se registró el número de unidades formadoras de colonias (UFC) por gramo de cacao fresco.

\subsection{Análisis estadístico}

Las variables que se midieron durante el tiempo de fermentación (5 días) fueron: azúcares reductores $(\mathrm{mg} / \mathrm{g}), \mathrm{pH}$ tanto en la testa mucilaginosa como en el cotiledón, porcentaje de humedad de los granos frescos, concentración de bacterias lácticas, bacterias acéticas, levaduras y aerobio mesófilos (UFC/g). Para las variables asociadas con la concentración de bacterias se trabajó con 2 réplicas, para cada sitio de muestreo. Para el análisis de las variables anteriores se utilizaron modelos mixtos de coeficientes aleatorios. Otro grupo de variables determinadas en campo fue la temperatura ambiental y la temperatura de proceso, en este grupo de variables se estableció un ANOVA no paramétrico de muestras independientes. Para el análisis, se utilizó el software estadístico R en su versión 3.5.0, se utilizó la librería "nlme" para el ajuste de modelos mixtos de coeficientes aleatorios y se utilizó la librería "stat" con la función Kruskal. En el test para la realización del ANOVA no paramétrico [18] se trabajó con una significancia del 5\% en los contrastes de hipótesis utilizados.

\section{Resultados y discusiones}

\subsection{Análisis físico-químicos: Parámetros de fermentación}

En la figura 1 se presenta la temperatura ambiental y de fermentación durante 5 días de fermentación evaluadas en tres unidades productivas de Florida. No se presentaron diferencias estadísticamente significativas entre los tres puntos de muestreo ( $p$ $>0.05$ ), tanto para la temperatura ambiental como la temperatura de fermentación. A partir de las 48 horas de fermentación, se presentó un aumento en la temperatura, evidenciando la actividad microbiana en la masa de cacao (Figura 1).

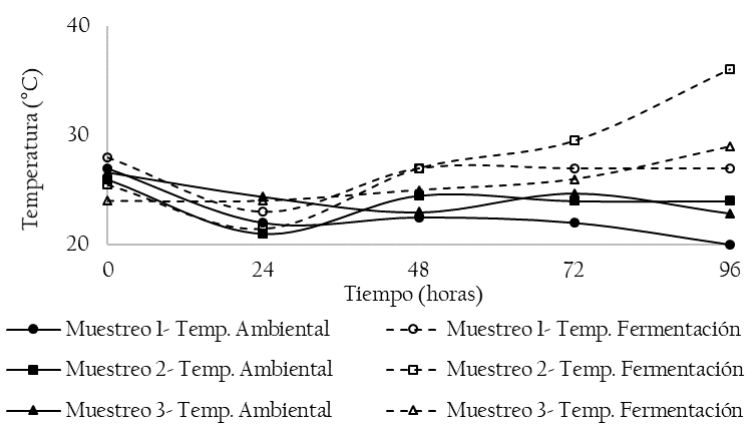

Figura 1. Perfil de temperatura ambiental y de fermentación en los tres puntos de muestreo durante 5 días de fermentación. Muestreo 1 (M1: Unidad productiva 1, abril de 2018), Muestreo 2 (M2: Unidad productiva 2, mayo de 2018) y Muestreo 3 (M3: Unidad productiva 3 , junio de 2018).

En la fermentación desarrollada en los puntos de muestreo 1,2 y 3 , se presentaron temperaturas medias de fermentación de 26,27 y $25^{\circ} \mathrm{C}$, respectivamente. Las temperaturas alcanzadas en las fermentaciones espontáneas se encuentran entre los 45 y $50{ }^{\circ} \mathrm{C}$, e incluso pueden ser superiores resultando en la disminución de la población microbiana [7]. Bajas temperaturas durante la fermentación de cacao indica una inadecuada infraestructura (Tabla 1).

Ale et al. [3] evaluaron diferentes tipos de materiales y su efecto en la fermentación de granos de cacao (madera, plástico, acero inoxidable y hojas em pila); quienes encontraron que el método tradicional (hojas en pila) producía la mejor calidad en términos de los estándares aceptables. Pero la caja de madera tenía un alcance muy cercano en la calidad de la actuación con hojas de montón. 
En la figura 2 se presenta la concentración celular de levaduras. La concentración de este grupo microbiano no presentó diferencias estadísticamente significativas entre puntos de muestreo $(p>$ $0.05)$ y presentaron diferencias estadísticamente significativas entre días de muestreo $(p<0.05)$. En el muestreo 1, la concentración de levaduras presentó una concentración inicial de $5.27 \pm 0,00$ y alcanzó $7.50 \pm 0.19 \log \mathrm{UFC} / \mathrm{g}$ a las 96 horas con un crecimiento constante en los días evaluados. En el muestreo 2, la concentración de levaduras presentó una concentración inicial de $4.68 \pm 0.08$ y alcanzó $7.04 \pm 0.05 \log$ UFC/g a las 48 horas, y a partir de ese momento presenta una disminución para reportar a las 96 horas una concentración celular de $5.01 \pm 0.06 \log \mathrm{UFC} / \mathrm{g}$. En el muestreo 3, se presentó una concentración inicial de $1.99 \pm 0.55$ $\log$ UFC/g y alcanzó una concentración de $7.85 \pm$ $0.34 \mathrm{log}$ UFC/g a las 72 horas y a partir de esa hora disminuyó. A las 96 horas se observó una disminución de la concentración celular $(6.94 \pm$ $0.10 \log \mathrm{UFC} / \mathrm{g}$ ). En las fermentaciones espontáneas de cacao al inicio del proceso de fermentación del grano de cacao (primeras 24-48 h), las levaduras son los microorganismos dominantes [19]. Las levaduras son las principales responsables de la despectinización de la pulpa de cacao, la producción de etanol y la producción de granos de cacao con aromas y caracteres típicos de chocolate [20]. En el presente estudio, el crecimiento de las levaduras está relacionado con la temperatura de fermentación, observándose que cuando la temperatura aumenta por encima de $27{ }^{\circ} \mathrm{C}$ se presenta una disminución en la concentración celular, tal como se evidenció en el muestreo 2 a partir de las 48 horas.

En la Figura 3, se presenta la concentración de BAL medidas en el tiempo de muestreo. Se presentaron diferencias estadísticamente significativas entre puntos de muestreo y entre días muestreados $(p<0.05)$.

Para el muestreo 2 y 3, la concentración celular inicial fue de $2.34 \pm 0.37$ y $1.48 \pm 0.00 \log \mathrm{UFC} / \mathrm{g}$ hasta llegar a las 96 horas a $6.44 \pm 0.02$ y 8.02 $\pm 0.64 \mathrm{log} \mathrm{UFC} / \mathrm{g}$, respectivamente, presentando un comportamiento similar. Mientras que para el muestreo 1 a partir de las 48 horas de fermentación se presentó un

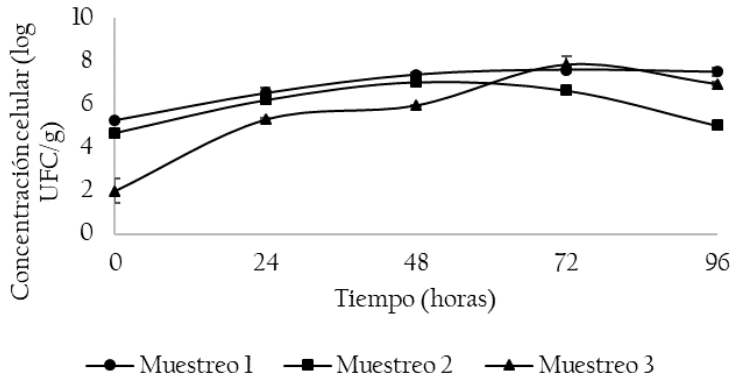

Figura 2. Concentración de levaduras $(\log \mathrm{UFC} / \mathrm{g})$ durante los muestreos 1, 2 y 3. Muestreo 1 (M1: Unidad productiva 1, abril de 2018), Muestreo 2 (M2: Unidad productiva 2, mayo de 2018) y Muestreo 3 (M3: Unidad productiva 3 , junio de 2018).

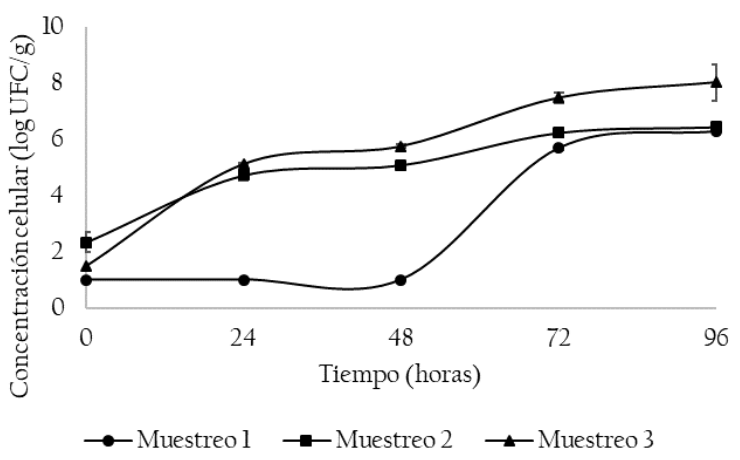

Figura 3. Concentración de bacterias lácticas (log UFC/g) en los muestreos 1, 2 y 3. Muestreo 1 (M1: Unidad productiva 1, abril de 2018), Muestreo 2 (M2: Unidad productiva 2, mayo de 2018) y Muestreo 3 (M3: Unidad productiva 3 , junio de 2018).

incremento considerable de $1.00 \pm 0.00$ a $6.28 \pm 0.00$ $\log \mathrm{UFC} / \mathrm{g}$. A medida que la fermentación continúa y el mucílago de cacao se drena, más aire ingresa a la masa de pulpa y grano de cacao en fermentación, lo que crea las condiciones ideales para el crecimiento de BAL y BAA de forma consecutiva entre las 24 y 72 horas de fermentación [7].

En la Figura 4 se presentan los resultados de la concentración celular de bacterias ácido acéticas. No se presentan diferencias estadísticamente significativas entre los puntos muestreados $(p>$ 0.05), sin embargo, para el muestreo 1 se evidencia una caída en la concentración celular a partir de la hora 72. En el muestreo 2 y 3, se evidencia un crecimiento constante de las células con una concentración inicial de $2.55 \pm 0.20$ y $2.80 \pm 0.01$ $\log \mathrm{UFC} / \mathrm{g}$, respectivamente. En el muestreo 1, la 
concentración inicial de las bacterias inicia en $5.08 \pm$ $0.05 \log$ UFC/g y alcanza una concentración de 6.04 $\pm 0.00 \mathrm{log}$ UFC/g a las 48 horas de fermentación, con una reducción a las 96 horas a concentración de $1.00 \pm 0.00 \log \mathrm{UFC} / \mathrm{g}$.

El comportamiento en el muestro 1 se podría explicar, por qué en el último día de fermentación (entre la hora 72 y 96), se presentó una disminución en la temperatura de fermentación (de 22 a $20{ }^{\circ} \mathrm{C}$ ), temperaturas muy inferiores a las reportadas en los puntos de muestreo 2 y 3 . Para el muestreo 2 y 3 se evidenció un aumento en la concentración celular a partir de las 24 horas de fermentación, dicho aumento, coincide con el inicio de los volteos en la fermentación, procedimiento que permite la oxigenación de la masa de cacao. Las BAA en particular las especies de Acetobacter, oxidan el etanol producido por las levaduras en ácido acético (oxidación parcial para la generación de ATP) [21] y el ácido láctico producido por las BAL. Esta última reacción genera calor que hace que la pulpa de cacao en fermentación aumente a $45-50{ }^{\circ} \mathrm{C}$, también considerada esencial para la fermentación exitosa y el desarrollo del sabor del chocolate [22].

En la figura 5, se presenta la concentración celular de aerobios mesófilos. No se presentaron diferencias estadísticamente significativas entre puntos de muestreo $(p<0.05)$, sin embargo, se presentaron diferencias estadísticamente significativas entre los días de fermentación evaluados $(p>0.05)$. Para los tres puntos de muestreo evaluados (M1, M2 y M3), la concentración celular aumentó constantemente, con concentraciones iniciales de $4.67 \pm 0.08,3.41$ \pm 0.15 y $2.46 \pm 0.15 \mathrm{log} \mathrm{UFC} / \mathrm{g}$ alcanzando concentraciones celulares a las 96 horas de 7.21 $\pm 0.10,6.23 \pm 0.07$ y $8.20 \pm 0.09 \mathrm{log} \mathrm{UFC} / \mathrm{g}$, respectivamente.

Las bacterias lácticas, acéticas y las bacterias entéricas pueden ser contabilizadas como aerobias mesófilas, lo cual se relaciona con las concentraciones celulares alcanzada por estos microrganismos.

En la Figura 6 se presenta la concentración de azúcares reductores en el tiempo. Se presentaron diferencias estadísticamente significativas entre puntos y días de muestreo $(p<0.05)$. En el muestreo 1 y 3 presentan una concentración inicial de $39.79 \pm$

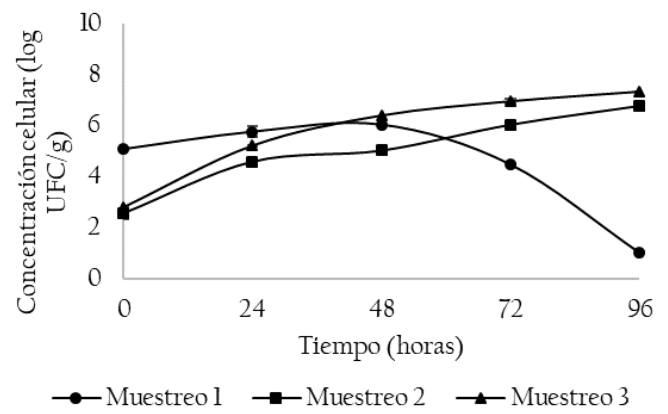

Figura 4. Concentración de bacterias ácido acéticas $(\log \mathrm{UFC} / \mathrm{g}$ ) en los muestreos 1, 2 y 3 . Muestreo 1 (M1: Unidad productiva 1, abril de 2018), Muestreo 2 (M2: Unidad productiva 2, mayo de 2018) y Muestreo 3 (M3: Unidad productiva 3, junio de 2018).

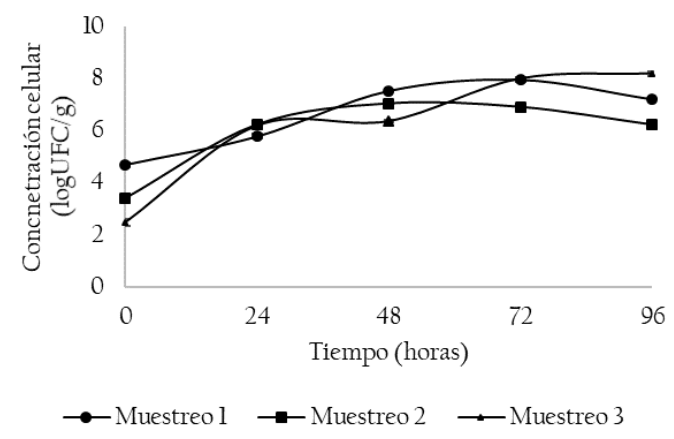

Figura 5. Concentración de aerobios mesófilos (log $\mathrm{UFC} / \mathrm{g}$ ) de los muestreos 1, 2 y 3. Muestreo 1 (M1: Unidad productiva 1, abril de 2018), Muestreo 2 (M2: Unidad productiva 2, mayo de 2018) y Muestreo 3 (M3: Unidad productiva 3, junio de 2018).

1.52 y $25.98 \pm 0.72 \mathrm{mg} / \mathrm{g}$, respectivamente. A las 24 horas de fermentación se evidencia un aumento en la concentración de azúcares reductores $(50.89 \pm 1.28$ y $60.06 \pm 2.16 \mathrm{mg} / \mathrm{g}$, respectivamente). Lo anterior se puede explicar porque la pulpa de cacao posee sacarosa, la cual puede ser se hidrolizada en glucosa $\mathrm{y}$ fructosa, por la actividad de la enzima invertasa de las levaduras [19]. Comportamientos similares fueron reportados por Racine et al. [23] donde la concentración de glucosa y fructosa permanece igual a las 24 horas con respecto a la concentración inicial de fermentación en pulpa de cacao. El consumo de azúcares (glucosa) para los muestreos 1, 2 y 3 , fueron de $64.40,88.78$ y $98.27 \%$, respectivamente. Se han obtenido resultados superiores mayores al 95\% a las 48 horas de fermentación [23]. 


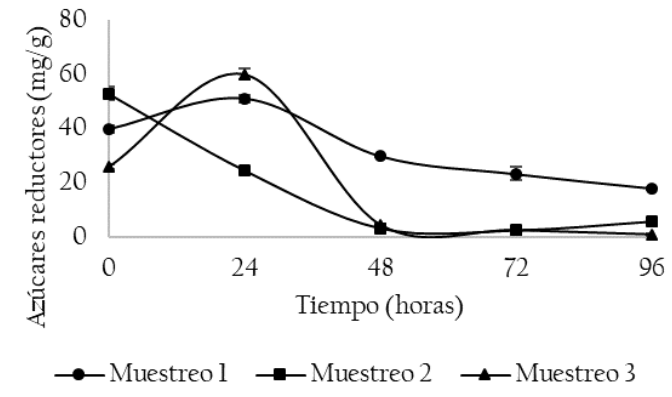

Figura 6. Concentración de azúcares reductores durante fermentación de los granos de cacao. Muestreo 1 (M1: Unidad productiva 1, abril de 2018), Muestreo 2 (M2: Unidad productiva 2, mayo de 2018) y Muestreo 3 (M3: Unidad productiva 3, junio de 2018).

En la figura 7 se presentan los resultados de $\mathrm{pH}$ de la testa mucilaginosa y del cotiledón. Se presentan diferencias estadísticamente significativas para el pH en la testa mucilaginosa tanto para los puntos de muestreo como para los días evaluados $(p<0.05)$. En el muestreo 1, el aumento de $\mathrm{pH}$ a partir de la hora 48 coincide con el aumento en la concentración de BAL (de $1.00 \pm 0.00 \log$ UFC/g y alcanzó una concentración de $5.68 \pm 0.05 \mathrm{log}$ UFC/g a las 48 horas) (figura 3). Lo anterior se puede explicar por la conversión del ácido cítrico en ácido láctico y ácido acético provocando un aumento del $\mathrm{pH}$ de 3,0 a 4,0, debido a los mayores valores de pKa de estos últimos ácidos orgánicos en comparación con el ácido cítrico [21]. El crecimiento de levaduras fue constante durante las fermentaciones (figura 2) y presentaron reservas de azucares fermentables (figura 6). El agotamiento de las fuentes de energía glucosa y fructosa, generó un aumento continuo de las concentraciones de etanol, ácido láctico y ácido acético ácido láctico y acético, y el aumento de la temperatura de la masa de la pulpa de cacao provocando un descenso de los recuentos de BAL y los recuentos de levaduras [7]. No se presentaron diferencias estadísticamente significativas para el $\mathrm{pH}$ en el cotiledón tanto para los puntos de muestreo como para los días evaluados $(p>0.05)$. Los valores de $\mathrm{pH}$ iniciales para la testa mucilaginosa (3.0 - 4.0) y cotiledón (alrededor de 7.0 antes de la fermentación) [7] coinciden con los valores del presente estudio. En el muestreo 2, el pH de la testa y del cotiledón tiende al equilibrarse. El pH final de los granos de cacao después del proceso de fermentación que ocurre es muy importante ya que el tipo de producto de la proteólisis enzimática de la proteínas (precursores de sabor y aroma) cambian con el $\mathrm{pH}$ [10]. Se cree que el pH interno del grano de cacao debe disminuir entre $\mathrm{pH} 5.0$ y 5.5 para permitir una buena actividad de las proteasas endógenas que son esenciales para la degradación de las proteínas del grano [24].

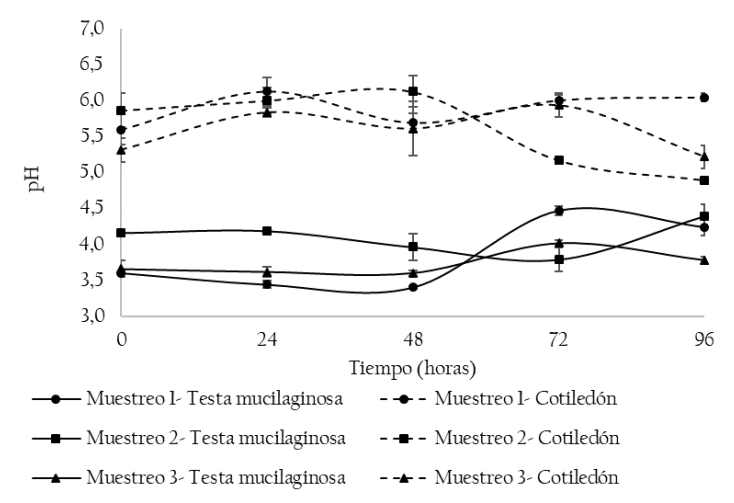

Figura 7. Comportamiento del $\mathrm{pH}$ durante fermentación de los granos de cacao. Muestreo 1 (M1: Unidad productiva 1, abril de 2018), Muestreo 2 (M2: Unidad productiva 2, mayo de 2018) y Muestreo 3 (M3: Unidad productiva 3, junio de 2018).

En el cuadro 2 se presenta el porcentaje de granos fermentados según la prueba de corte y el índice de fermentación. Se presentaron diferencias estadísticamente significativas para el índice de fermentación en los puntos de muestreo evaluados $(p<0.05)$.

Para los muestreos evaluados se observaron bajos porcentajes de granos bien fermentados, siendo el punto 2 y 3 los valores más bajos. Lo anterior, puede ser debido a varios factores como el corto tiempo de fermentación, la mezcla de granos de tamaños diferentes e incluso la infraestructura para la fermentación. Los resultados de la prueba de corte, coinciden con los resultados del índice de fermentación donde se consideran granos bien fermentados con índices superiores a 1.0. López et al. [10] evaluaron 3 estados de madurez de cacao CCN51, donde determinaron índices de fermentación de entre 0.8 y 1.1 desde las 24 a las 96 horas de fermentación respectivamente, para un estado de fermentación 3. 
El índice de fermentación es determinado por espectrofotometría, y estos cambios pueden ser evidenciados debido a la descomposición de los pigmentos de antocianina durante la fermentación con la formación posterior de más productos de condensación de antocianina [25].

Tabla 2. Porcentaje de fermentación visual e índice de fermentación de puntos de muestreo evaluados.

\begin{tabular}{|c|c|c|c|c|c|}
\hline \multicolumn{2}{|c|}{ Parámetro } & \multirow{2}{*}{$\frac{\text { M1 }}{59}$} & \multirow{2}{*}{$\frac{\text { M2 }}{5}$} & \multirow{2}{*}{$\frac{\text { M3 }}{35}$} & \multirow{2}{*}{$\frac{\text { Referencia }}{>65(\text { NTC 1252) }}$} \\
\hline$\% \mathrm{FV}^{*}$ & Buena & & & & \\
\hline & Incompleta & 36 & 10 & 35 & $<35$ (NTC 1252) \\
\hline & Mala (Violetas) & 5 & 85 & 30 & 0 (NTC 1252) \\
\hline \multicolumn{2}{|c|}{$\begin{array}{l}\text { Índice de } \\
\text { Fermentación }\end{array}$} & $0.78^{a}$ & $0.58^{b}$ & $0.70^{c}$ & $\begin{array}{l}>1.0 \text { (Enmanuel } \\
\text { et al. [29]) }\end{array}$ \\
\hline
\end{tabular}

Nota: *Fermentación visual (FV) (tablas de fermentación Batista, [31]). ${ }^{a, b, c}$ letras diferentes representan diferencias estadísticamente significativas entre puntos.

\section{Conclusiones}

Los parámetros químicos como el índice de fermentación y físicos como el porcentaje de granos fermentados, permiten evaluar la calidad de la fermentación de los granos de cacao que para efectos de este estudio fue baja. El alto valor en el pH del cotiledón, el porcentaje de fermentación visual (prueba de corte) y el índice de fermentación, indicaron una baja fermentación de los granos de cacao. El crecimiento microbiano está determinado por la temperatura de fermentación, que a su vez está influenciada por la temperatura ambiental por falta de aislamiento de las condiciones externas en las unidades productivas. Las respuestas bioquímicas de una correcta fermentación de cacao pueden variar entre diferentes localidades, este trabajo representa un punto de partida para trabajos similares y comparativos de calidad, por lo cual se debe estudiar las interacciones bioquímicas y la influencia en el crecimiento microbiano.

\section{Agradecimientos}

A la comunidad de Cacaocultores Biocacao de La Union, Florida (Valle del Cauca) por su colaboración y disposición en el proceso.

\section{Referencias}

[1] M. A. Chaux and M. A. Pérez, ¿Nuevos caminos para los cacaos especiales de Colombia? Una experiencia desde el proyecto Coexca 2012 - 2017, Fundación. Bogotá D.C, 2017.

[2] H. Rawel, G. Huschek, S. Tchewonpi, and T. Homann, "Cocoa Bean ProteinsCharacterization, Changes and Modifications due to Ripening and Post-Harvest Processing", Nutr. Rev., vol. 11, no. 2, p. 428, 2019, DOI: 10.3390/nu11020428.

[3] M. O. Ale, A. A. Akintade, and O. O. Orungbemi, "Effects of Fermentation Techniques on the Quality of Cocoa Beans", Int. J. Agric. Biosyst. Eng., vol. 12, no. 8, pp. 251-254, 2018.

[4] R. H. Ordoñez-Araque, E. F. Landines-Vera, J. C. Urresto-Villegas, and C. F. CaicedoJaramillo, "Microorganisms during cocoa fermentation: systematic review", Foods Raw Mater., vol. 8, no. 1, pp. 155-162, 2020, DOI: 10.21603/2308-4057-2020-1-155-162.

[5] D. Kadow, N. Niemenak, S. Rohn, and R. Lieberei, "Fermentation-like incubation of cocoa seeds (Theobroma cacao L.) - Reconstruction and guidance of the fermentation process", LWT - Food Sci. Technol., vol. 62, no. 1, pp. 357-361, 2015, DOI: 10.1016/j.lwt.2015.01.015.

[6] M. Apriyanto, "Analysis of Amino Acids in Cocoa Beans Produced during Fermentation by High Performence Liquid Chromatography (HPLC)", Int. J. Food Ferment. Technol., vol. 7 , no. 1 , p. 25 , 2017, DOI: $10.5958 / 2277-$ 9396.2017.00003.4.

[7] L. De Vuyst and S. Weckx, "The cocoa bean fermentation process: from ecosystem analysis to starter culture development", J. Appl. Microbiol., vol. 121, no. 1, pp. 5-17, 2016, DOI: $10.1111 /$ jam.13045.

[8] T. S. Ooi, A. S. Y. Ting, and L. F. Siow, "Influence of selected native yeast 
starter cultures on the antioxidant activities, fermentation index and total soluble solids of Malaysia cocoa beans: A simulation study", Lwt, vol. 122, no. July 2019, p. 108977, 2020, DOI: 10.1016/j.lwt.2019.108977.

[9] S. Soumahoro, H. G. Ouattara, M. Droux, W. Nasser, S. L. Niamke, and S. Reverchon, "Acetic acid bacteria (AAB) involved in cocoa fermentation from Ivory Coast: species diversity and performance in acetic acid production", J. Food Sci. Technol., vol. 57, no. 5, pp. 1904-1916, 2020, DOI: $10.1007 / \mathrm{s} 13197-$ 019-04226-2.

[10] M. del P. López, J. C. Núñez, M. S. H. Gómez, and M. D. L. Tovar, "Physicochemical and microbiological dynamics of the fermentation of the CCN51 cocoa material in three maturity stages", Rev. Bras. Frutic., vol. 41, no. 3, pp. 1-13, 2019, DOI: 10.1590/0100-29452019010.

[11] J. Warren et al., "Experimentally modelling cocoa bean fermentation reveals key factors and their influences", Food Chem., vol. 302, no. 1, p. 125335, 2020, DOI: 10.1016/j.foodchem.2019.125335.[12] CEDAF, "Guía Técnica El Cultivo de Cacao", 2009. DOI: 10.1016/S0365-6691(10)70034-4.

[12] O. B. Gourieva, K.B. and Tserrevitinov, "Method of evaluating the degree of fermentation of cocoa beans. USSR Patent no. 646254", 1979.

[13] I. A. D. Steinau, “Evaluación de la incidencia de la fermentación en la calidad del grano de cacao trinitario en caluco, sonsonate, el salvador", 2017.

[14] G. L. Miller, "Use of Dinitrosalicylic Acid Reagent for Determination of Reducing Sugar", Anal. chemestry, vol. 31, no. March, p. 60147, 1959, DOI: 10.1021/ac60147a030.

[15] T. Romero-Cortes, V. Robles-Olvera, G. Rodriguez-Jimenes, and M. Ramírez-Lepe, "Isolation and characterization of acetic acid bacteria in cocoa fermentation", African J.
Microbiol. Res., vol. 6, no. 2, pp. 339-347, 2012, DOI: 10.5897/AJMR11.986.

[16] K. Beheshti-Maal and N. Shafiee, "Isolation and Identification of A Novel Strain of Acetobacter ghanensis KBMNS-IAUF-6 from Banana Fruit, Resistant to High Temperature and Ethanol Concentration", Iran. J. Med. Microbiol., vol. 13, no. 4, pp. 251-265, 2019, DOI: $10.30699 /$ ijmm.13.4.251.

[17] R. C. Team, "R: A laguage and enviroment for statistical computing." 2013.

[18] L. De Vuyst and F. Leroy, "Functional role of yeasts, lactic acid bacteria and acetic acid bacteria in cocoa fermentation processes", FEMS Microbiol. Rev., vol. 44, no. 4, pp. 432453, 2020, DOI: 10.1093/femsre/fuaa014.

[19] G. V. M. Pereira et al., "Great intraspecies diversity of Pichia kudriavzevii in cocoa fermentation highlights the importance of yeast strain selection for flavor modulation of cocoa beans", LWT - Food Sci. Technol., vol. 84, pp. 290-297, 2017, DOI: 10.1016/j.lwt.2017.05.073.

[20] L. De Vuyst and F. Leroy, "Functional role of yeasts, lactic acid bacteria and acetic acid bacteria in cocoa fermentation processes", FEMS Microbiol. Rev., vol. 44, no. 4, pp. 432453, 2020, DOI: 10.1093/femsre/fuaa014.

[21] V. T. T. Ho, G. Fleet, and J. Zhao, "Unravelling the contribution of lactic acid bacteria and acetic acid bacteria to cocoa fermentation using inoculated organisms", Int. J. Food Microbiol., vol. 279, no. September 2017, pp. 43-56, 2018, DOI: $10.1016 /$.

[22] K. C. Racine et al., "Development and characterization of a pilot-scale model cocoa fermentation system suitable for studying the impact of fermentation on putative bioactive compounds and bioactivity of cocoa", Foods, vol. 8, no. 3, pp. 1-20, 2019, DOI: 10.3390/foods8030102.

[23] V. T. T. Ho, J. Zhao, and G. Fleet, "Yeasts are essential for cocoa bean fermentation", Int. J. 
Food Microbiol., vol. 174, pp. 72-87, 2014, DOI: 10.1016/j.ijfoodmicro.2013.12.014.

[24] E. O. Afoakwa, J. Quao, F. S. Takrama, A. S. Budu, and F. K. Saalia, "Changes in total polyphenols, o-diphenols and anthocyanin concentrations during fermentation of pulp preconditioned cocoa (Theobroma cacao) beans", Int. Food Res. J., vol. 19, no. 3, pp. 1071-1077, 2012. 